\title{
RELATÓRIO SOBRE O ANTE-PROJETO DA PARTE ESPECIAL DO CÓDIGO PENAL (Parte Primeira)
}

Departamento de Direito Penal e Processual Penal

Prof. Luis Alberto Machado

\section{I - INTRODUÇĀO}

1. A Comissão designada, em 06 de setembro de 1983, pelo Excelentíssimo Senhor Ministro da Justiça apresentou seu trabalho de elaboração do Ante Projeto da Parte Especial do C. Penal em 12 de julho de 1984. Em 17 de julho de 1984 o Senhor Ministro, "considerando que é do interesse do Governo o amplo e democrático debate sobre o anteprojeto", pela Portaria no. 304, de 17.07.84, autorizou a publicação do texto, em caráter prioritário, fixando o dia 21 de agosto de 1984 como o último do prazo para a apresentação de sugestões. Fica evidente, pelo simples confronto das datas, a exiguidade do prazo para análise, estudo e debate sobre matéria tão relevante, em prejuízo da própria tecnicidade do Ante Projeto, pela impossibilidade material da participação da comunidade científica.

Esses fatos não podem, porém, impedir que o Departamento de Direito Penal e Processual Penal da Universidade Federal do Paraná aponte as posições que lhe pareçam as mais corretas, ainda que, impossibilitadas de serem havidas como sugestões pelo decurso do prazo, sejam recebidas como críticas científicas ao que, a seu ver, o Ante Projeto tem de falho.

Indicado para apresentar, em nome do Departamento, Relatório sobre o Ante Projeto, inicio-o com a análise crítica do Capítulo I DOS CRIMES CONTRA A VIDA.

\section{II - ANÁLISE DOS TIPOS}

1. O Ante Projeto troca a numeração ordinal dos $\S \S 10$. e $2^{\circ}$. do art. 121 , sem qualquer motivo de ordem científica, já que estava assente ser, o $\$ 10$., privilegiamento do tipo de homicidio, e, o $\$ 20$., qualificação.

$\mathrm{O}$ inciso I mantém a qualificativa da "paga, promessa de recompensa, ou outro motivo torpe". Melhor seria se buscasse inspiração no C. Penal de 1969, que acrescentou a cupidez, a excitação e a satisfação 
de desejos sexuais como formas de qualificação do homicidio. A criminalidade sexual violenta tem aumentado de forma assustadora e é necessário o aparelhamento do $\mathrm{C}$. Penal para poder responder às diferentes condutas. O homicídio com finalidades sexuais ou por interesses de ganho (não compreendidos na paga e na promessa de recompensa) não é, hoje, exceção no D. Penal. Ademais, tratam-se de formas de conduta como modelos de interpretação analógica (não analogia integradora), pela alocução "ou por outro motivo torpe", que ficam melhor com a redação do C. Penal de 1969 (art. 121, § 20., II).

O inciso IV deveria conter a alocução "com surpresa", qualificativa que não está contida na redação atual do C. Penal, nem na do Ante Projeto. Note-se que a surpresa tem caráter qualificador, sendo um desvalor da conduta mais acentuado, e não se inclui na interpretação analógica. Por isso, o C. Penal de 1969 a incluiu, expressamente, dentre as circunstâncias que qualificam o tipo de homicídio (art. 121, § 20., IV).

Da mesma forma poder-se-ia atualizar a redação do inciso $\mathrm{V}, \S 10$., art. 121, do Ante Projeto, fazendo-a assim: "para facilitar ou assegurar a execução, a ocultação, a impunidade ou vantagem de outro crime". Não apenas o assecuramento, como a facilitação, são desvalores dessa conduta. Não há motivo para deixar a facilitação incidir no homicidio simples, enquanto o assecuramento, com a mesma carga desvalorativa, enquadra-se no qualificado.

2. O § $2^{\circ}$., do art. 121 é igual ao $§ 10$. do $\mathrm{C}$. Penal atual. A diferença está em que, enquanto no $\mathrm{C}$. Penal em vigor a redução da pena é facultativa, no Ante Projeto é obrigatoria Parece-me bastante superior a redação do Ante Projeto, pois que evita disputas jurisprudenciais a esse respeito.

3. O Ante Projeto inova ao inserir a eutanásia no $\S 3^{\circ}$. do art. 121. Não apenas por enfrentar, isentando-a de pena, uma conduta altamente discutível, como também pela redação. $O$ isento da pena é o médico, não o parente próximo que sofre, com o doente, as suas dores, decorrentes de ineludível doença incurável (teoria da substituição: o agente substitui-se à vítima). Ora, o médico não pode alegar dor pela dor alheia, pois que, profissionalmente, está obrigado a enfrentá-la. Ademais, a conduta da eutanásia está compreendida no privilegiamento do delito. Fica-se, assim, diante de uma contradição: se o filho, sabedor e consciente de doença incurável e morte próxima do pai, para aliviar a dor de ambos e da família, no eufemismo da redação do Ante Projeto, "antecipa morte próxima", no maximo beneficiar-se-á do privilegiamento do tipo de homicidio ( $\$ 20$.). Mas se for o médico, não parente, quem "antecipa a morte próxima", estará isento da pena!

Melhor será eliminar o § $3^{\circ}$. do Ante Projeto.

4. Nenhuma novidade quanto à conduta culposa que resulta em morte de alguém.

Porém, o $\S 40$ do atual C. Penal ( $\$ 5^{\circ}$. do Ante Projeto) teve a sua 
redação modificada. A redação do $\S 40$. estava em ótima técnica. 0 $\S 50$. do Ante Projeto renova uma distinção do Direito Romano: culpa grave. Sabe-se que a divisão entre culpa leve, grave e gravíssima, ainda que adotada por alguns penalistas, é empréstimo do direito privado. $\mathrm{Pe}$ nal e modernamente, a nível de censura na culpa em sentido estrito,deve situar-se na capacidade de previsibilidade do agente, não na pré-fixação de grau de culpa: Entendo, desse modo, que a redação atual do C. Penal vigente deve prevalecer.

5. O mesmo raciocínio serve para a análise do $\S 6^{\circ}$. do Ante Projeto ( $\S 50$. do C. Penal). A redação atual é tecnicamente perfeita. O mesmo, entretanto, não se pode dizer do Ante Projeto. $\mathrm{O}$ texto, aliás, parece até truncado:

“O juiz pode, no homicídio culposo, deixar de aplicar a pena, se o agente, ou seu ascendente, descendente, cônjuge ou irmão, sofre lesão corporal grave, ou se ocorre a morte de um destes." (Ante Projeto, art. 121, § 60.)

É a teoria da substituição posta em lei, mas de forma defeituosa. Primeiro, não se determina a causalidade entre a conduta do agente e os resultados que, potencialmente, 0 atingiriam com tal gravidade, que a sanção penal tornar-se-ia não desnecessária, mas demasiada (fundamento exclusivamente retributivista da pena). Não é a simples relação de parentesco que significa dor para o agente, de modo a se desnecessitar da sanção penal; parentes podem estar brigados e odiarem-se.

A redação atual é mais técnica do que a proposta pelo Ante Projeto: o juiz examina se, no caso concreto, "as conseqüências da infração atingiram o próprio agente de forma tão grave que a sanção penal se torna desnecessária".

6. Também não me convenceu a diminuição do limite máximo da pena do homicidio simples, de vinte para quinze anos de reclusão.' Isso porque, mantido o limite mínimo de doze anos da pena do homicídio qualificado, perde-se a elasticidade da aplicação das penas dos homicídios simples e qualificado, que a tradição penal tem recomendado.

7. O crime de induzimento, instigação ou auxílio a suicídio (C. Penal, art. 122; Ante Projeto, art. 122) passou a ser de resultado natural, exigindo, no tipo, a ocorrência da lesão grave ou da morte, meras condições objetivas de punibilidade no C. Penal atual. Assim, o tipo objetivo passou a ter, ao lado do desvalor de conduta, o desvalor de resultado natural.

Além dessa modificação, merecedora de apoio, o Ante Projeto altera as penas das formas qualificadas, previstas no parágrafo único do art. 122: enquanto no C. Penal a pena é duplicada na ocorrência de uma qualificativa, no Ante Projeto a pena situa-se entre dois a cinco anos. Portanto, enquanto o C. Penal fixa causas de especial aumento de pena, o Ante Projeto cria o tipo qualificado. 
Acontece que a pena das formas qualificadas situa-se em um mínimo de dois e um máximo de cinco anos. Ora, o crime simples tem a pena entre um e cinco anos. Qual a diferença entre o tipo simples e o tipo qualificado? Nenhuma. As penas são as mesmas.

O C. Penal de 1969 trouxe uma inovação, no tocante ao suicídio, que mereceria figurar no Ante Projeto, que é da provocação indireta ao suicídio (cf. art. 122, § $2^{\circ}$.). 0 tipo estrutura-se nos maus tratos, desumanos e reiterados, praticados com abuso de autoridade, conduzindo ao suicídio.

8. A redação do Ante Projeto para o crime de infanticídio (art. 123) merece ser retificada. Em boa hora retirou-se o suplício do reconhecimento do estado puerperal e colocou-se, como elemento do tipo, a "honoris causa".

Mas tem um defeito de elaboração: "sob a influência deste" (do parto). Vale dizer, substituíu-se uma fórmula de difícil configuração prática - o estado puerperal - por outra de duvidosa cientificidade. $\mathrm{O}$ que significa a influência do parto? A construção será, certamente, tormentosa e tortuosa.

Como critério de justiça, o Ante Projeto cria um parágrafo único, dispondo que "quem concorre para o crime incide nas penas do art. 121 e parágrafos". Essa forma indireta de tipificar a conduta do partícipe do crime de infanticídio não é, certamente, a mais correta. Melhor seria a inserção de um parágrafo no art. 121, dando, à mãe que mata o filho, durante o parto ou logo após, por motivo de honra, uma causa de especial diminuição de pena. Com isso, como circunstância pessoal não elementar do tipo, punir-se-ia o partícipe com o tipo de homicídio, simples ou qualificado, conforme o caso concreto.

9. O crime de aborto, no Ante Projeto (arts. 124 "usque" 128), não traz grandes novidades em relação ao C. Penal atual (art. 124 "usque" 128). Muda, isso sim, o "quantum" das penas. $E$, com isso, cria algumas contradições: o tipo qualificado pelo resultado, previsto no art. 127 do Ante Projeto, traz penas menores do que as do tipo básico. Assim, por exemplo, no aborto provocado por terceiro, sem o consentimento da gestante, a pena situa-se entre três e oito anos no tipo simples (art. 126) e entre dois e sete anos, no tipo qualificado pelo resultado (art. 127, denominação do Ante Projeto). Isto é, se do aborto, não consentido pela gestante, nada Ihe resultar, a pena pode ser de até oito anos; se resultar-lhe lesões corporais de natureza grave, a pena pode ser de até cinco anos; e se resultar-Ihe a morte, a pena poderá ser de até sete anos!

Melhor estaria a posição do C. Penal atual, que prevê, em lugar de tipos qualificados, causas de especial aumento de penas. Evitar-seia a discrepância contida no Ante Projeto.

O Ante Projeto mantém o aborto necessário em caso de gravidez resultante de estupro (art. 128, inciso II), contemplado no C. Penal atual da mesma forma (art. 128, inciso II). Mas traz novidade de pés- 
sima inspiração: o aborto eugênico; diz o art. 128, inciso III, que não haverá o crime de aborto se

"há fundada probabilidade, atestada por outro médico, de o nascituro apresentar graves e irreversíveis anomalias físicas ou mentais."

Exige o consentimento do marido, quando a mulher for casada (art. 128, p. único).

O primeiro defeito que se poderia apontar é transformar-se uma conduta típica, portanto objetivamente desvalorada, em conduta atípi$\mathrm{ca}$, pois que exclui a ilicitude. O C. Penal atual é mais técnico, eliminando a censura pessoal do agente na prática do crime. $O$ desvalor objetivo da conduta, o tipo, existe. O que se apaga é a censura. Não se pode dizer que o médico, nas circunstâncias previstas pelo art. 128 do Ante Projeto, tenha agido licitamente. A sua conduta não pode ser equiparável à da legítima defesa. O que se faz é isentá-lo de pena, não censurá-lo.

O segundo defeito é não se incluir a gravidez resultante de atentado violento ao pudor como causa do aborto necessário, ao lado do estupro.

O terceiro defeito, e grande, é o não enfrentamento do problema da permissibilidade, ou não, do aborto. Procura-se, "concessa venia" hipocritamente, criar aberturas para o aborto, de duvidosas inspirações, em lugar de examinar-se, em debate sério, público e geral, a possível permissibilidade do aborto.

Melhor seria - desde que se não quer abordar os grandes temas com amplos e públicos debates, com prazos razoáveis para a apresentação de sugestões e com a tomada da opinião pública através de plebiscitos, como nos países mais cultos - manter-se os dispositivos do atual C. Penal.

10. Esta a primeira parte do Relatório sobre o Ante Projeto de Parte Especial do Código Penal.

Curitiba, 25 de agosto de 1984.

Prof. Titular L. A. MACHADO, Diretor da Faculdade 